\title{
Saline volume and local anesthetic concentration modify the spread of epidural anesthesia
}

Toshiyuki Okutomi MD, Makiko Minakawa MD, Sumio Hoka MD

Purpose: To examine the effects of the volume of saline and the concentration of local anesthetic on the quality of anesthetic level.

Methods: One hundred and fifty two patients received thoracic epidural anesthesia were allocated into two groups; mepivacaine $1 \%$ (75 patients) and $1.5 \%$ (77 patients). Each group was randomly divided into three subgroups depending on epidural saline volumes of $I \mathrm{ml}, 5 \mathrm{ml}$, or $10 \mathrm{ml}$. Fifteen minutes after the injection of $10 \mathrm{ml}$ mepivacaine, the dermatome levels of hypesthesia to cold and pinprick were determined by an individual blinded to the saline volume.

Results: The number of spinal segments with hypesthesia to cold in the three subgroups in the mepivacaine $1 \%$ group were 12.5 [6-20], 13 [8.5-20.5] and 12.5 [6.5-22], respectively (median [range]). The segments in the mepivacaine 1.5\% group were 12 [7-18.5], $14[8.5-19]^{*}$ and I5 [6-23]*, respectively ${ }^{*} P<0.05$ vs I-ml group). The number of spinal segments with hypesthesia for pinprick in the three subgroups in the $1 \%$ mepivacaine group were $10.5[2-22], 10.5[4-17]$ and 11 [4-19], respectively. The segments in the mepivacaine $1.5 \%$ group were 12 [7.5-16], 12 [7.5-17] and II.5 [5-22.5], respectively. Saline volume did not alter the anesthetic level of the mepivacaine $1 \%$, although it did affect the anesthetic spread of the mepivacaine $1.5 \%$. In both groups, a differential nerve block was elicited in the $5 \mathrm{ml}$ and $10 \mathrm{ml}$ saline subgroups.

Conclusion: When a large volume of saline is administered prior to local anesthetic, more differential blockade and a greater extent of anesthesia may be elicited.

Objectif : Examiner les effets du volume de solution salée et de la concentration d'anesthésique local sur la qualité de l'anesthésie.

Méthode : Cent cinquante-deux patients qui ont reçu une anesthésie péridurale thoracique ont été répartis en deux groupes : mépivacaïne $1 \%$ (75 patients) et $1,5 \%$ (77 patients). Chaque groupe a été divisé au hasard en trois sous-groupes selon les volumes de solution salée péridurale administrée, 1,5 ou $10 \mathrm{ml}$. Quinze minutes après l'injection de $10 \mathrm{ml}$ de mépivacaïne, le niveau du dermatome touché d'hypoesthésie au froid et à la piqûre a été déterminé par une personne ignorant le volume de solution salée donné.

Résultats : Le nombre de segments médullaires atteints d'hypoesthésie au froid a été, dans les trois sous-groupes qui ont reçu la mépivacaine $1 \%$, de 12,5[6-20], $13[8,5-20,5]$ et de $12,5[6,5-22]$, respectivement (médiane [étendue]). Dans le groupe qui a reçu la mépivacaiine $1,5 \%$, les segments ont été : 12 [7-18,5], 14 [8,5-19]* et 15 [6-23]*, respectivement $(* P<0,05$ vs le groupe $1 \mathrm{ml})$. Le nombre de segments atteints d'hypoesthésie à la piqûre a été, dans les trois sous-groupes de mépivacainne $1 \%$, de 10,5 [2-22], 10,5 [4-17] et 11 [4-19], respectivement. Les segments du groupe de mépivacaïne $1,5 \%$ ont été de 12 [7,5-16], 12 [7,5-17] et de 11,5 [5$22,5]$, respectivement. Le volume de solution salée n'a pas changé le niveau anesthésique de la mépivacainne $1 \%$, mais il a eu un effet sur l'étendue anesthésique de mépivacaine 1,5\%. Dans les deux groupes, un blocage nerveux différentiel a été provoqué dans les sous-groupes de patients qui ont reçu 5 et $10 \mathrm{ml}$ de solution salée.

Conclusion : Lorsqu'on administre un grand volume de solution salée avant l'anesthésique local, on peut obtenir davantage de blocage différentiel et une plus grande étendue de l'anesthésie.

From the Department of Anesthesiology, Kitasato University School of Medicine, 1-15-1 Kitasato, Sagamihara, Kanagawa 228-8555, Japan. Address correspondence to: Toshiyuki Okutomi MD, Phone: +81-42-778-8616; Fax: +81-42-778-9427

Accepted for publication June 17, 1999 


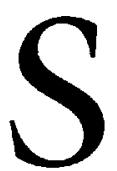

UDDEN loss of resistance is an indicator as to whether or not the epidural needle has advanced through the Ligamentum flavum. For this technique, a small amount of saline solution is usually used as the needle is advanced and may be injected into the epidural space. Occasionally, large volumes are inadvertently injected into the space, particularly when it is difficult to place the epidural catheter. The relationship between the volume of epidural saline and the spread of the subsequent anesthetic was originally reported by Iwama, ${ }^{1}$ where a greater volume of saline increased the spread in the segments of hypesthesia and analgesia with mepivacaine $2 \%$. However, our recent study demonstrated that there was no relationship between the volume of saline and the spread of mepivacaine $1 \%$ in segments with hypesthesia for cold. ${ }^{2}$ This inconsistency may be due to the different concentrations of the local anesthetic used in the two studies. Therefore, the purpose of this study was to examine the effect of local anesthetic concentration and saline volume on anesthetic levels and quality of epidural blockade.

\section{Methods}

The study protocol was approved by our hospital's investigation committee on ethics. The study was a single- blinded clinical trial. We enrolled 152 ASA physical status I-III patients undergoing upper abdominal surgery who gave informed consent.

Each patient received $10-15 \mathrm{mg}$ diazepam po as premedication. Intravenous access was obtained in all patients. They were placed in the left lateral position on a horizontal operating table. Epidural puncture was performed aseptically by an attending anesthetist at the $\mathrm{T}_{7-8}$ level of the intervertebral space using a reusable 17G winged Tuohy needle (47B-1170, Hakko-Shouji Co., Tokyo, Japan) by a paramedian approach with the loss of resistance method using $<1$ $\mathrm{ml}$ normal saline solution.

Patients enrolled in the study were divided into two groups; 75 patients for epidural mepivacaine $1 \%$ (group I) and 77 patients for epidural mepivacaine $1.5 \%$ (group II). The patients in each group were randomly allocated into three subgroups to receive saline volumes of $1 \mathrm{ml}, 5 \mathrm{ml}$, or $10 \mathrm{ml}$ into the epidural space before the epidural was started. This randomization was performed by dividing the last two figures of the patients' identification (ID) numbers by three. Those patients whose figures were divisible were allocated to the $1 \mathrm{ml}$ group, while the patients whose ID divided by three with one left over were allocated to the $5 \mathrm{ml}$ group, and with two left over were allocated to the $10 \mathrm{ml}$ group.
After injection of $1 \mathrm{ml}, 5 \mathrm{ml}$ or $10 \mathrm{ml}$ saline through the needle at $1 \mathrm{ml} \cdot \mathrm{sec}^{-1}$, the epidural catheter (Epineed EN-C1795, Terumo Co. Tokyo, Japan) was threaded into the epidural space $3 \mathrm{~cm}$ cephalad from the epidural tap. After confirming negative aspiration of cerebrospinal fluid and blood, $2 \mathrm{ml}$ mepivacaine $1 \%$ were injected with the patients in the left lateral position as a test dose to confirm correct epidural catheter placement in both groups. Patients were turned to the supine horizontal position. Five minutes after injection of the test dose, we confirmed again that the epidural catheter was not placed in the subarachnoid space by assessing the degree of motor blockade and asking the patient if there was numbness in their legs. Then, $10 \mathrm{ml}$ mepivacaine $1 \%$ in group I or $10 \mathrm{ml}$ mepivacaine $1.5 \%$ in group II were administered over $30 \mathrm{sec}$ through the epidural catheter.

To determine sensory blockade, assessment of the spread of hypesthesia by cold sensation and pain stimulus on both sides of the body according to a dermatomal chart (above the 2nd sacral dermatome), using cotton soaked in rubbing alcohol and pinprick, $15 \mathrm{~min}$ after epidural injection of $10 \mathrm{ml}$ mepivacaine $1 \%$ and mepivacaine $1.5 \%$ in groups I and II, respectively, was performed by an individual blinded to the amount of saline administered. The assessment of hypesthesia for pain stimulus was started from the "unblocked" region, and moved to "blocked" region. The extent of the hypesthesia was calculated as the average dermatome of both sides if the block levels for both sides were not coincident.

Lactated Ringer's solution was administered at 10 $\mathrm{ml} \cdot \mathrm{kg}^{-1} \cdot \mathrm{hr}^{-1}$ during these procedures. Arterial pressure and heart rate were determined automatically every five

TABLE Characteristics of patients assigned to the three subgroups in cach group of the study (mean $\pm \mathrm{SD}$ ).

\begin{tabular}{|c|c|c|c|}
\hline \multirow[b]{2}{*}{ Characteristic } & \multicolumn{3}{|c|}{ Subgroups of $1 \%$ mepivacaine } \\
\hline & $1-m l$ group & 5 -ml group & 10-ml group \\
\hline $\mathrm{n}$ & 23 & 23 & 23 \\
\hline $\operatorname{Sex}(M / F)$ & $15 / 8$ & $13 / 10$ & $13 / 10$ \\
\hline Age (yr) & $60 \pm 10$ & $54 \pm 14$ & $52 \pm 14$ \\
\hline Height $(\mathrm{cm})$ & $160 \pm 8$ & $161 \pm 11$ & $161 \pm 9$ \\
\hline \multirow[t]{2}{*}{ Weight (kg) } & $56 \pm 9$ & $62+14$ & $60 \pm 13$ \\
\hline & \multicolumn{3}{|c|}{ Subgroups of $1.5 \%$ mepivacaine } \\
\hline Cbaracteristic & $l-m l$ group & 5 -mlgroup & 10-ml groutp \\
\hline $\mathrm{n}$ & 23 & 23 & 23 \\
\hline $\operatorname{Sex}(M / F)$ & $17 / 6$ & $12 / 11$ & $16 / 7$ \\
\hline Age (yr) & $54 \pm 11$ & $59 \pm 9$ & $65 \pm 11$ \\
\hline Height $(\mathrm{cm})$ & $162 \pm 6$ & $159 \pm 10$ & $161 \pm 8$ \\
\hline Weight (kg) & $60 \pm 9$ & $57 \pm 12$ & $57 \pm 11$ \\
\hline
\end{tabular}

No significant differences were observed. 
minutes, and arterial oxygen saturation was continuously monitored. When the systolic pressure decreased to $80 \mathrm{mmHg}$ or to $<70 \%$ of the baseline pressure, $1 \mathrm{mg}$ etilefrine $i v$, a sympathomimetic vasoconstrictor, was administered.

After these procedures, general anesthesia was induced with thiopental or propofol and the anesthesia was maintained by nitrous oxide and sevoflurane or propofol-fentanyl combined with epidural anesthesia. Vecuronium was used as a muscle relaxant. Anesthesia was adequate in all patients for upper abdominal surgery and there were no serious complications.

Differences between all variables among the three subgroups were tested using Kruskal-Wallis tests, followed by Mann-Whitney U-tests. The difference between the number of segments with hypesthesia for cold and pinprick was tested using Wileoxon. A $P$ value $<0.05$ was considered significant. Results are expressed as mean $\pm S D$ in characteristic data for patients and median [range] in anesthetic level.

\section{Results}

Of the 152 patients, one had a blood tap, two had a spinal tap, five had failure of catheter placement and six had heavy premedication. Therefore, 69 patients in each group were studied. There were no differences in age, height or weight among the two groups (Table). The number of spinal segments with hypesthesia to cold in the $1 \mathrm{ml}, 5 \mathrm{ml}$ and $10 \mathrm{ml}$ saline groups in the mepivacaine $1 \%$ group were $12.5[6-20], 13$ [8.5-20.5] and 12.5 [6.5-22], respectively (median [range]) (Figure 1). Those segments in the mepivacaine $1.5 \%$ group were 12 [7-18.5], 14 [8.5-19] and 15 [6-23], respectively (Figure 2). The number of segments with hypesthesia for coldness in the $5 \mathrm{ml}$ and $10 \mathrm{ml}$ saline groups in the $1.5 \%$ mepivacaine group was greater than that in the $1 \mathrm{ml}$ saline group ( $P<0.05$ ) (Figure 2 ). The number of spinal segments with hypesthesia for pinprick in the $1 \mathrm{ml}, 5 \mathrm{ml}$ and $10 \mathrm{ml}$ saline groups in the $1 \%$ mepivacaine group were 10.5 [2-22], $10.5[4-17]$ and 11 [4-19], respectively (Figure 1). The segments in the mepivacaine $1.5 \%$ group were 12 [7.5-16], 12 [7.5-17] and 11.5 [5-22.5], respectively (Figure 2 ). In both groups, the differential nerve block or differences between the number of segments with hypesthesia for cold and pinprick were elicited in the $5 \mathrm{ml}$ and $10 \mathrm{ml}$ groups (Figures 1, 2).

\section{Discussion}

Our principal findings are that the hypesthetic level to cold after mepivacaine $1.0 \%$ administration was not different among the three saline volume subgroups while the level after mepivacaine $1.5 \%$ administration was

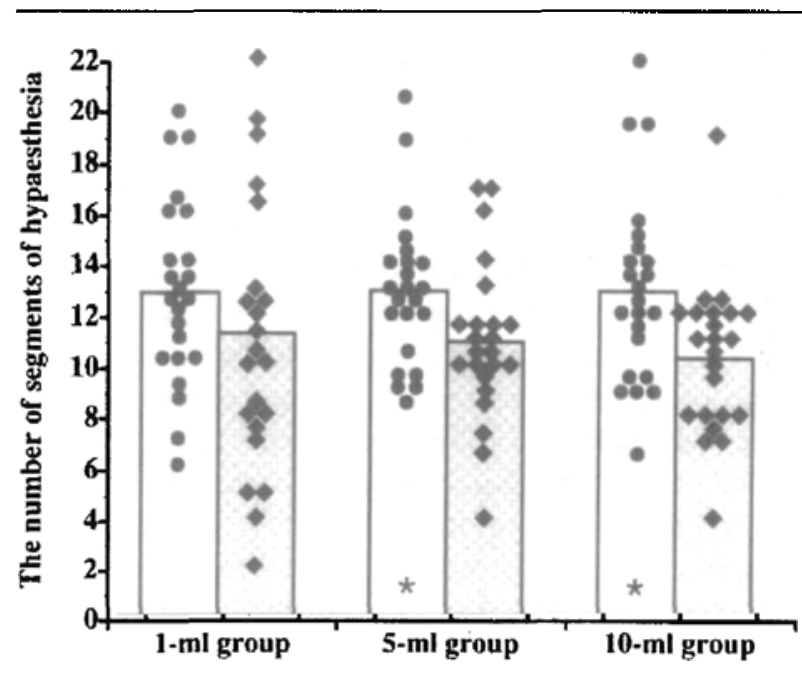

FIGURE 1 The number of dermatomes for hypesthesia for cold stimulation and pinprick in three groups of different saline volumes prior to $10 \mathrm{ml}$ of mepivacaine $1 \%$. The top level of cach bar represents the average segment in each group. Closed circle: the number of dermatomes for hypesthesia for cold sensation; closed diamond: the number of dermatomes for hypesthesia for pinprick stimulus in each patient. ${ }^{*} P<0.05$ vs the number of dermatomes for hypesthesia for pinprick in the same group.

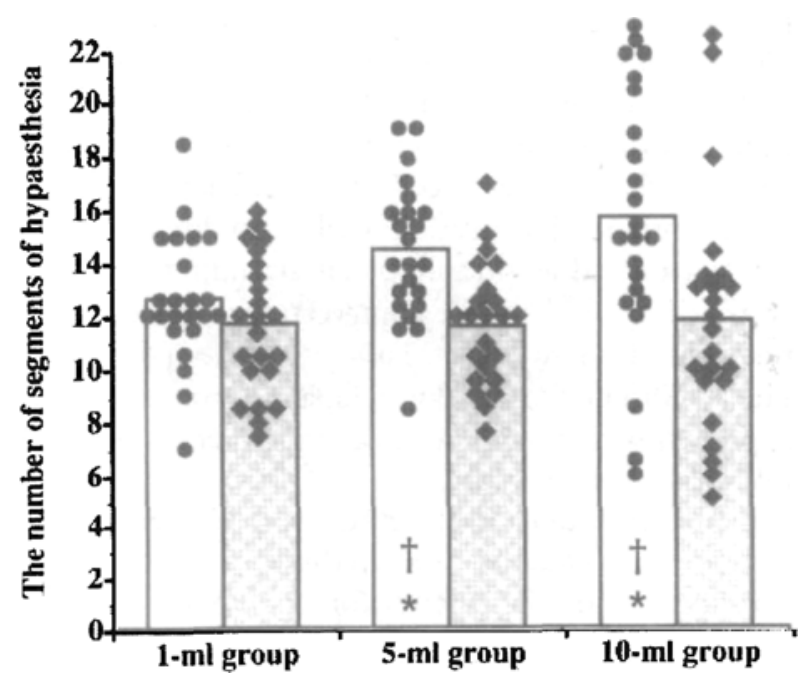

FIGURE 2 The number of dermatomes for hypesthesia for cold srimulation and pinprick in three groups of different saline volumes prior to $10 \mathrm{ml}$ of $1.5 \%$ mepivacaine. The top level of each bar represents the average segment in each group. Closed circle: the number of dermatomes for hypesthesia for cold sensation; closed diamond: the number of dermatomes for hypesthesia for pinprick stimulus in each patient. ${ }^{*} P<0.05$ vs the number of dermatomes for hypesthesia for pinprick in the same group. $\boldsymbol{P}^{\prime}<$ $0.05 v$ the number of dermatomes for hypesthesia for cold stimulation in 1-ml group. 
dependent on the previously injected saline volume used during the loss of resistance method procedure.

The volume-anesthesia relationship for epidural anesthesia was originally reported by Bromage. ${ }^{3} \mathrm{He}$ assumed that the epidural volume-anesthesia relationship was linear, so that doubling the epidural volume would double the number of spinal segments blocked. However, others have shown that a step increase in volume results in relatively small differences in the spread of anesthetic effect. ${ }^{4,5}$ In addition, no correlation between the volume injected into the epidural space and the spread of anesthetic were reported by Duggan et $a l^{6}$ and Paul et al. ${ }^{7}$ Since we did not examine the different volumes of local anesthetic, it is obvious that the effects of pre-injected saline volumes are not comparable with the different volumes of anesthetic as they reported. However, it is possible that pre-injecting different saline volumes changes the epidural pressure gradient or the spread segment of the saline and affects the spread of subsequent local anesthetic. If there is no difference among the spread of different volumes of local anesthetic as in their reports, the spread of different volumes of saline would not affect the subsequent local anesthetic. Therefore, their results for the volume effect on the spread of different volumes of local anesthetic are meaningful when we consider the implication for our study.

On the other hand, a relationship between epidural saline and the spread of the following anesthetic has been also reported. Iwama ${ }^{l}$ showed that when a large volume of saline was used with the loss of resistance method it caused a greater extent of hypesthesia and analgesia, assessed with an alcohol swab, and a pinprick after administration of mepivacaine $2 \%$. In our previous study, using mepivacaine 1\% epidurally, hypesthesia for cold was independent of the saline volume with the loss of resistance method whereas hypesthesia for pinprick (analgesia) was attenuated proportionally to the saline volume. ${ }^{2}$ The different results in these two studies are likely due to the difference of mepivacaine concentrations. Thus, the anesthetic effect could appear in the dermatome where pre-injected saline spread after a high concentration of the local anesthetic as in Iwama's study was administered. In the case of mepivacaine $1.0 \%$, the spread may be similar to that of mepivacaine $1.5 \%$. However, the anesthetic may be diluted by saline in the area of the upper level of spread so that temperature discrimination was impaired in the patients. If correct, this explains why the hypesthetic level for cold sensation after mepivacaine $1.5 \%$ administration is widely spread proportionally to the saline volume while those after $1 \%$ mepivacaine administration was independent of saline volume.
We also considered the effect of increased epidural pressure from the saline volume on the volume effect in this study. Usubiaga $e t a l^{8}$ suggested that the block height related to the epidural pressure generated after injection. In this study, we injected the local anesthetic five minutes after the test dose which followed the injected saline solution into the epidural space. Even though the elevated pressure was maximum at the end of the injection and the pressure decreased to a plateau in less than a few minutes, ${ }^{9,10}$ the pressure generated by the injected solution could still influence the spread of the solution. We assumed that the spread of local anesthetic administered five minutes after the test dose in this study was more affected by the epidural pressure than that of the local anesthetic ten minutes after the test dose in our previous study.

Generally, different concentrations of local anesthetics block different types of nerve fibres. The smallest fibres, sympathetic fibres and those transmitting temperature discrimination, are more sensitive than those transmitting pain. The more the local anesthetic is diluted by saline, the greater the differential nerve block. This phenomenon is a well known characteristic in subarachnoid anesthesia. Green ${ }^{11}$ mentioned that this may be due to the progressive dilution of anesthetic by the cerebrospinal fluid so that its concentration decreases as the distance from the injection site increases, resulting in a zone in which only temperature discrimination is impaired while pinprick sensation is intact. When a larger saline solution is injected into the epidural space, it is possible that it also dilutes the local anesthetic. In fact, in our previous study, the results showed that the greater volume of saline with the loss of resistance method caused a more obvious differential nerve block.

Air is also used to attest the loss of resistance during epidural puncture instead of saline. Saberski et al..$^{12}$ showed that complications were more frequent with the loss of resistance method using air than with saline. The complications include pneumocephalus, spinal cord and nerve root compression, retroperitoneal air, subcutaneous emphysema, venous air embolism and incomplete analgesia. From our results, a large saline solution may modulate the spread of local anesthetic and thus saline also may have disadvantages over air.

In conclusion, the hypesthetic level for cold after a low concentration of local anesthetic administration was independent of the volume of saline whereas the hypesthetic level for pain sensation was attenuated proportionally to the saline volume. On the other hand, the level for cold after a higher concentration of local anesthetic administration was spread proportionally to the saline volume whereas the hypesthetic level for pain was independent of the saline solution. 


\section{References}

1 Iwama $H$. Injection volume of saline with loss of resistance method may affect the spread of epidural anesthesia (Letter). Anesthesiology 1997; 86: 507-8.

2 Okutomi T, Hoka S. Epidural saline solution prior to local anaesthetic produces differential nerve block. Can J Anaesth 1998; 45: 1091-3.

3 Bromage PR. Spread of analgesic solutions in the epidural space and their site of action: a statistical study. $\mathrm{Br}$ J Anaesth 1962; 34: 161-78.

4 Grundy EM, Ramamurthy S, Patel KP, Mani $M$, Winnic $A P$. Extradural analgesia revisited. A statistical study. Br J Anaesth 1978; 50: 805-9.

5 Park Wr, Hagins FM, Rivat EL, Macnamara TE. Age and epidural dose response in adult men.

Anesthesiology 1982; 56: 318-20.

6 Duggan J, Bowler GMR, McClure JH, Wildsmith JAW. Extradural block with bupivacaine: influence of dose, volume, concentration and patient characteristics. $\mathrm{Br}$ J Anaesth 1988; 61: 324-31.

7 Paul DL, Wildsmith JAW. Extradural pressure following the injection of two volumes of bupivacaine. $\mathrm{Br} \mathrm{J}$ Anaesth 1989; 62: 368-72.

8 Usubiaga JE, Wikinski JA, Usubiaga LE. Epidural pressure and its relation to spread of anesthetic solutions in epidural space. Anesth Analg 1967; 46: 440-6.

9 Hirabayashi $\Upsilon$, Shimuzu $R$, Masuda I, Inoue S. Effect of extradural compliance and resistance on spread of extradural analgesia. Br J Anaesth 1990; 65: 508-13.

10 Okutomi T, Watanabe S, Goto F. Time course in thoracic epidural pressure measurement. Can J Anaesth 1993; 40: 1044-8.

11 Green NM. Area of differential block in spinal anesthesia with hyperbaric tetracaine. Anesthesiology 1958; 19: 45-50.

12 Saberski LR, Kondamuri S, Osinubi OrO. Identification of the epidural space: is loss of resistance to air a safe technique? A review of the complications related to the use of air. Reg Anesth 1997; 22: 3-15. 